\title{
Improved Hydrogen Generation from Formic Acid
}

A. Boddien, B. Loges, H. Junge, J.R. Noyes, F. Gärtner, M. Beller

This document appeared in

Detlef Stolten, Thomas Grube (Eds.):

18th World Hydrogen Energy Conference 2010 - WHEC 2010

Parallel Sessions Book 4: Storage Systems / Policy Perspectives, Initiatives and Cooperations

Proceedings of the WHEC, May 16.-21. 2010, Essen

Schriften des Forschungszentrums Jülich / Energy \& Environment, Vol. 78-4

Institute of Energy Research - Fuel Cells (IEF-3)

Forschungszentrum Jülich $\mathrm{GmbH}$, Zentralbibliothek, Verlag, 2010

ISBN: 978-3-89336-654-5 


\title{
Improved Hydrogen Generation from Formic Acid
}

\author{
Albert Boddien, Björn Loges, Henrik Junge, James R. Noyes, Felix Gärtner, \\ Matthias Beller, Leibniz-Institut für Katalyse e.V. an der Universität Rostock (LIKAT), \\ Germany
}

An adequate and sustainable supply of energy is one of the essential challenges for our future. Due to ever-increasing energy demands further improved technologies for the production, distribution, storage and conversion of energy are stringently necessary. In this respect a hydrogen economy would allow both for the increasing energy demand as well as the reduction of greenhouse gases. In this respect, a key issue is the current lack of safe and practical methods for onboard storage of hydrogen. Recently we and the groups of $G$. Laurenczy and S. Fukuzumi demonstrated independently that formic acid can be used as efficient storage material for hydrogen [1].

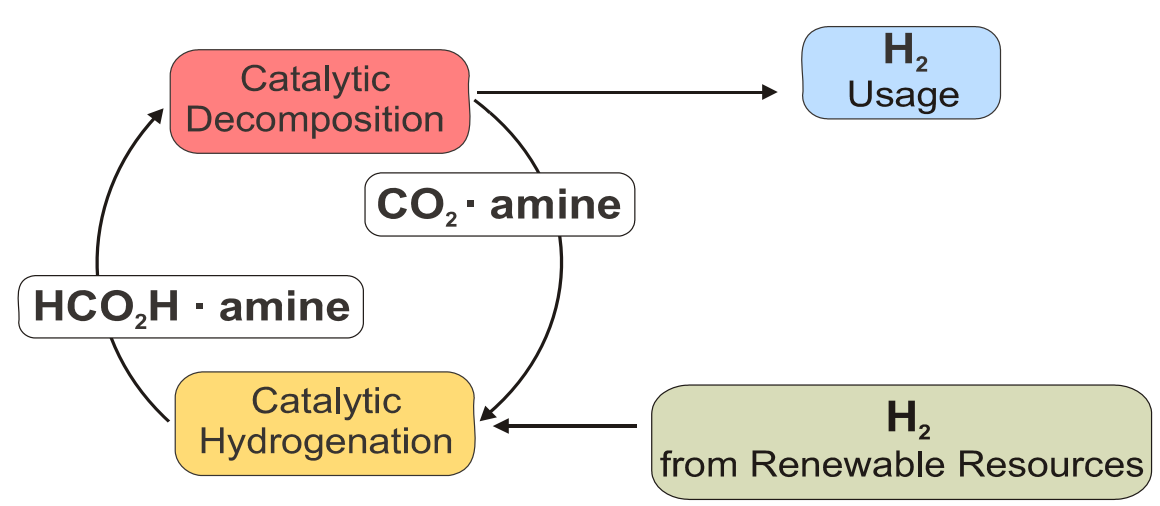

Figure 1

Applying in situ prepared ruthenium phosphine catalyst systems we could show the continuous generation of hydrogen at mild conditions (RT) from formic acid amine adducts [2]. More recently we investigated the influence of organic bases and of inorganic salt additives on the productivity and activity of the Ru-catalyzed hydrogen generation from formic acid [3]. While weaker bases decelerate the process, stronger bases like HexNMe2, DBN or MTBD gave excellent activities (Figure 2). 


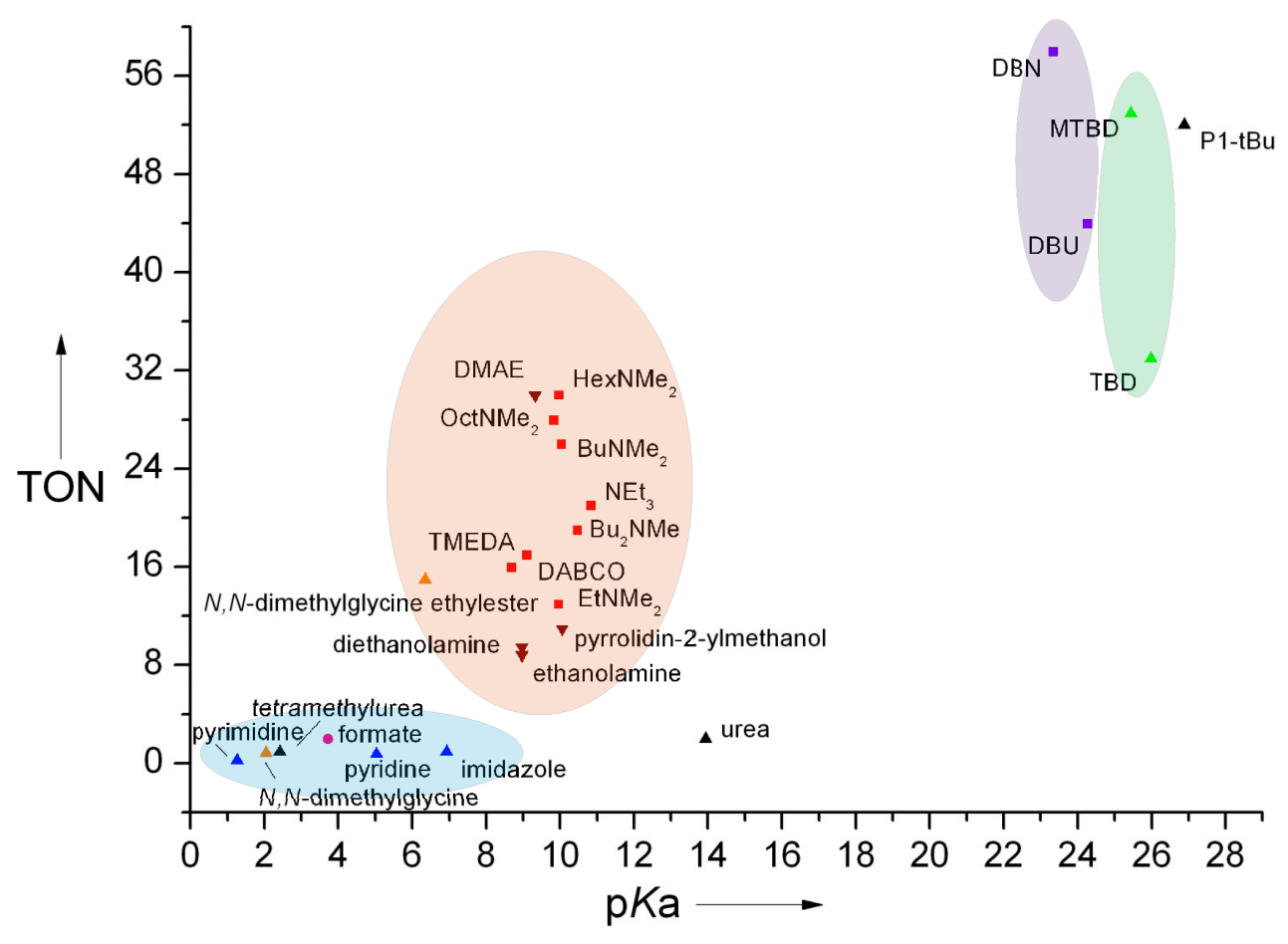

\section{Figure 2}

Moreover the presence of halide ions has also a significant influence. While the catalyst activity increase by $>450 \%$ with a [RuCl2(p-cymene)] 2 pre-catalyst by addition of 10 eq. of $\mathrm{KI}$, a decrease of the catalyst activity is observed by addition of $\mathrm{KBr}$ to a phosphine containing catalyst system. Noteworthy, applying a catalyst system containing [RuCl2(benzene)]2 and dppe with triethylamine $(3: 4$; amine to $\mathrm{HCO} 2 \mathrm{H})$ or $N, N$-dimethyl- $n$ hexylamine (4:5) a fast hydrogen generation is possible with full conversion within 2 hours.[4] Applying $20 \mathrm{~mL}$ of $5 \mathrm{HCO} 2 \mathrm{H} / 4 \mathrm{HexNMe} 2$ as substrate a TON of 5716 within 3 hours at $40^{\circ} \mathrm{C}$ was reached, which constituted the highest activity for our approach to hydrogen generation so far. After gas evolution had ceased, the catalyst was reactivated ten times by addition of formic acid. In the first run, a prolonged induction period was observed. The activity did not decrease significantly within the next 10 runs, and an overall TON $>60000$ was achieved (Figure 3a). 


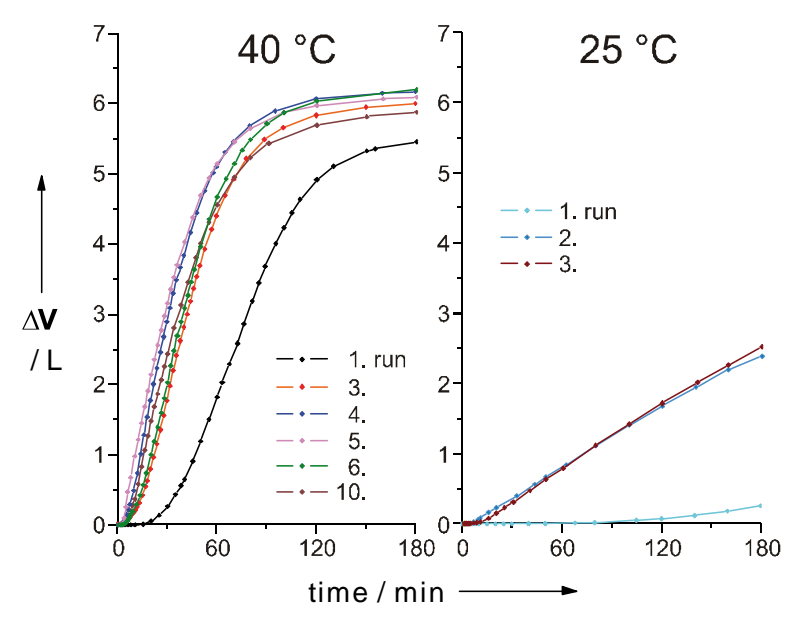

a

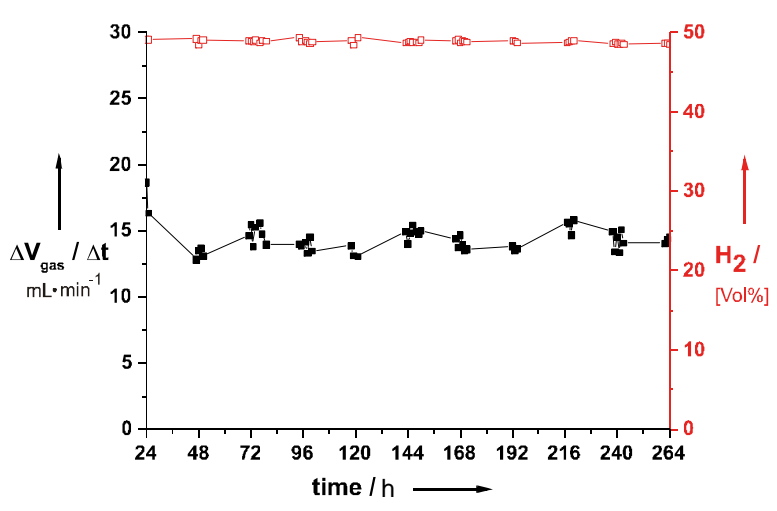

b

Figure 3

Based on these results, a continuous reactor was set up with $9.55 \mu \mathrm{mol}$ [RuCl2(benzene)]2 I 6 dppe $17.5 \mathrm{~mL}$ HexNMe2. The system worked for more than 11 days using commercial $99 \%$ formic acid from BASF SE as received. Gas output and hydrogen concentration were virtually constant during this time, and no signs of catalyst deactivation were observed (Figure 3b). Overall, 260000 turnovers were achieved, corresponding to TOF > $900 \mathrm{~h}-1$. This concept was proven to work in a small prototype model car driven by a hydrogen/air fuel cell, which has been coupled to an onboard hydrogen generation system using formic acid and a similar catalyst.

Furthermore, we could reveal the first light-driven iron-based catalytic system for hydrogen generation from formic acid, where hydrogen generation is possible under visible light irradiation and ambient temperature.[5] Applying a catalyst formed in situ from inexpensive Fe3(CO)12, 2,2':6'2"'-terpyridine and triphenylphosphine hydrogen generation is possible under visible light irradiation and ambient temperature. Applying 1,10-phenanthroline as $N$ ligand significant catalyst turnover numbers $(>100)$ are observed, which is the highest activity known to date for non-precious metal catalyzed hydrogen generation from formic acid. NMR, IR studies, and DFT calculations of iron complexes, which are formed under reaction conditions, confirm that PPh3 plays an active role in the catalyst cycle and that $\mathrm{N}$-ligands enhance the stability of the system (Figure 4). 


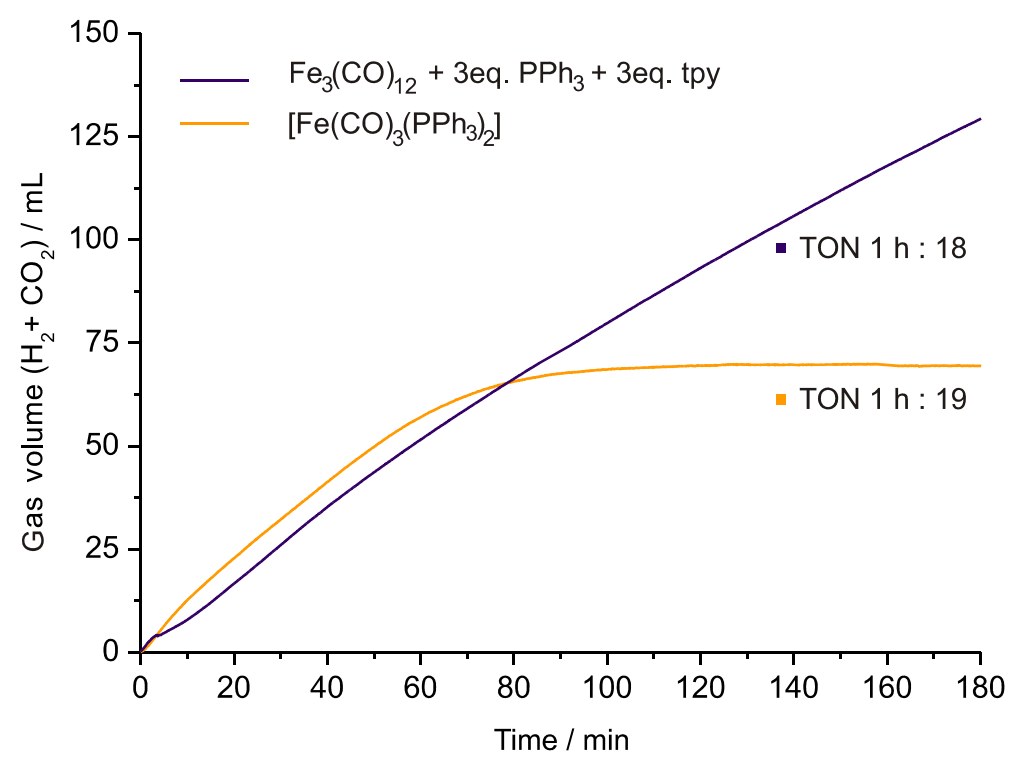

\section{Figure 4}

It is shown that the reaction mechanism includes iron hydride species which are generated exclusively under irradiation with visible light.

The present work demonstrates that hydrogen can be produced on demand even at room temperature without the need of high temperature reforming processes. In conclusion, we have shown that depending on the ruthenium pre-catalysts amines and halide additives have a significant influence on the catalyst activity. Moreover, under optimized conditions $>330 \mathrm{ml}$ hydrogen/h is generated from $5 \mathrm{~mL}$ formic acid/amine mixture, which allows for electrical applications. Beside we could show for the first time that also Fe-catalysts are capable of generating hydrogen from formic acid.

\section{References}

[1] C. Fellay, P. J. Dyson, G. Laurenczy, Angew. Chem. Int. Ed. 2008, 47, 3966-3968; Fukuzumi, S.; Kobayashi, T.; Suenobu, T. ChemSusChem. 2008, 1, 827-834; B. Loges, A. Boddien, H. Junge, M.Beller, Angew. Chem. Int. Ed. 2008, 120, 4026-4029.

[2] A. Boddien, B. Loges, H. Junge, M. Beller, ChemSusChem. 2008, 1, 751-758.

[3] H. Junge A. Boddien, Francesca Capitta, B. Loges, James R. Noyes, Serafino Gladiali,, M. Beller, Tetrahedron Letters. 2009, 1603-1606

[4] A. Boddien, B. Loges, H. Junge, F. Gärtner, J.R. Noyes, M. Beller, Adv. Synth. Catal. 2009, 351, 2517.

[5] A. Boddien, B. Loges, F. Gärtner, C. Torborg, K. Fumino, H. Junge, R. Ludwig, M. Beller, J. Am. Chem. Soc. 2010, DOI: ja-2010-00925n. 